Article

\title{
Optimized Support Vector Machines Combined with Evolutionary Random Forest for Prediction of Back-Break Caused by Blasting Operation
}

\author{
Qun Yu ${ }^{1}$, Masoud Monjezi ${ }^{2}$, Ahmed Salih Mohammed ${ }^{3}\left(\mathbb{D}\right.$, Hesam Dehghani $^{4}$, Danial Jahed Armaghani ${ }^{5, *(D)}$ \\ and Dmitrii Vladimirovich Ulrikh ${ }^{5}$
}

check for

updates

Citation: Yu, Q.; Monjezi, M.; Mohammed, A.S.; Dehghani, H.; Armaghani, D.J.; Ulrikh, D.V. Optimized Support Vector Machines Combined with Evolutionary Random Forest for Prediction of Back-Break Caused by Blasting Operation. Sustainability 2021, 13, 12797. https://doi.org/10.3390/ su132212797

Academic Editor: Guang-Liang Feng

Received: 9 October 2021

Accepted: 16 November 2021

Published: 19 November 2021

Publisher's Note: MDPI stays neutral with regard to jurisdictional claims in published maps and institutional affiliations.

Copyright: (c) 2021 by the authors. Licensee MDPI, Basel, Switzerland. This article is an open access article distributed under the terms and conditions of the Creative Commons Attribution (CC BY) license (https:/ / creativecommons.org/licenses/by/ $4.0 /)$.
1 School of Architecture and Civil Engineering, Shenyang University of Technology, Shenyang 110870, China; snoopy.351@hotmail.com

2 Department of Mining, Faculty of Engineering, Tarbiat Modares University, Tehran 14115-143, Iran; monjezi@modares.ac.ir

3 Civil Engineering Department, College of Engineering, University of Sulaimani, Sulaymaniyah 46001, Iraq; ahmed.mohammed@univsul.edu.iq

4 Department of Mining Engineering, Hamedan University of Technology, Hamedan 6516913733, Iran; dehghani@hut.ac.ir

5 Department of Urban Planning, Engineering Networks and Systems, Institute of Architecture and Construction, South Ural State University, 76, Lenin Prospect, 454080 Chelyabinsk, Russia; ulrikhdv@susu.ru

* Correspondence: danialarmaghani@susu.ru

Abstract: Back-break is an adverse event in blasting works that causes the instability of mine walls, equipment collapsing, and reduction in effectiveness of drilling. Therefore, it boosts the total cost of mining operations. This investigation intends to develop optimized support vector machine models to forecast back-break caused by blasting. The Support Vector Machine (SVM) model was optimized using two advanced metaheuristic algorithms, including whale optimization algorithm (WOA) and moth-flame optimization (MFO). Before the models' development, an evolutionary random forest (ERF) technique was used for input selection. This model selected five inputs out of 10 candidate inputs to be used to predict the back break. These two optimized SVM models were evaluated using various performance criteria. The performance of these two models was also compared with other hybridized SVM models. In addition, a sensitivity evaluation was made to find how the selected inputs influence the back-break magnitude. The outcomes of this study demonstrated that both the SVM-MFO and SVM-WOA improved the performance of the standard SVM. Additionally, the SVM-MFO showed a better performance than the SVM-WOA and other hybridized SVM models. The outcomes of this research recommend that the SVM-MFO can be considered as a powerful model to forecast the back-break induced by blasting.

Keywords: blasting; back-break; SVM; metaheuristic algorithms; moth-flame optimization; whale optimization algorithm

\section{Introduction}

Back-break $(B B)$ is an undesired outcome of blasting in mining operations. This phenomenon refers to the breaking into pieces of rocks exceeding the thresholds of the rear row of holes in a blast design [1]. Some undesirable impacts of the $B B$ include instability of rock mine wall, fallings, and increment of the overall cost of blasting [2,3]. There are three main categories of parameters which affect the $B B$; these categories include (1) parameters related to blast design, (2) explosive material characteristics, and (3) the rock mass traits and breaks. While the first and second types of variables are regarded as manageable, the third group is viewed as uncontrollable blasting variables [4-8]. The factors that may affect the $B B$ include low stiffness ratio, extreme burden, over stemming of the hole, and geological structure $[1,9,10]$. As many parameters affect $B B$, suitable appraisal and prediction of this 
environmental consequence are extremely challenging. The mentioned challenge can be solved using different, well-designed models for blasting pattern parameters. In addition, geological conditions should be observed and considered before blasting operations [11]. Many previous studies endeavored to forecast $B B$ through numerous machine learning (ML) techniques such as support vector machines (SVM), artificial neural networks (ANN), and so on [3,12-16]. Monjezi, Rezaei and Yazdian [14] developed two multiple-based techniques, namely multiple regression (MR) and fuzzy inference system (FIS) to forecast $B B$ induced by blasting. They used burden, the charge per delay, hole depth, specific drilling, stemming spacing, powder factor, and rock density as input variables. They also discovered the FIS model outperforms the MR model. The ANN, neuro-fuzzy and MR models were used by Esmaeili, Osanloo, Rashidinejad, Bazzazi and Taji [3] to forecast the $B B$ employing data of Sangan iron mine, Iran. Compared to other models, they demonstrated that the neuro-fuzzy model receives a superior performance. Using 10 input parameters, for the same problem, Monjezi, Ahmadi, Varjani and Khandelwal [13] developed an ANN model using a database comprising of 97 data samples. In addition to the ANN model, they suggested an MR equation for the $B B$ prediction. They successfully showed that the ANN model outperforms the MR model. Another study, which was conducted by Mohammadnejad, Gholami, Sereshki and Jamshidi [2], showed the applicability and practicability of the SVM for prediction of $B B$ and concluded that the SVM technique is a reliable and precise tool for the $B B$ prediction. Some other ML techniques, such as random forest and its optimized approaches, optimized fuzzy-rule techniques with rock engineering systems, and genetic-based models have been suggested in literature for forecasting $B B$ resulting from blasting [17-19]. The details of some recent studies on $B B$ prediction using ML and artificial intelligence (AI) techniques are described in Table 1. In this table, input variables of $B B$ predictive models together with the size of the database used by various researchers are presented. It is worth stating that these models have been used by other investigators in fields of blasting, rock mechanics, geotechnics, and civil and mining engineering [20-41].

The victorious utilizations of SVM and its associated combination variants in determining different geotechnical difficulties were informed by many scholars [49-52]. In the domain of blasting and its environmental effects, many scholars established SVM models to forecast ground vibration, fly-rock distance, rock fragmentation, and blast-caused rock movement $[24,53-55]$. The SVM is regarded as a robust method that can confidently determine geotechnical-related difficulties. Thus, this research concluded to utilize various hybrid SVM models to explain the $B B$ issue. It is necessary to remark that to the best of the authors' knowledge, the SVM models were implemented and offered in the domain of $B B$ forecast. Nevertheless, the application of innovative combined predictive models based on the idea of an SVM model optimized by any robust optimization methods are neglected in this domain. Therefore, the central role of this study is to utilize and propose the novel combination of SVM models in forecasting $B B$ extent. To accomplish this, the authors selected to use two renowned, robust, and fit optimization methods, including moth-flame optimization (MFO) and whale optimization algorithm (WOA), in integrated SVM models of this research. Consequently, two SVM-centered models, such as SVM-MFO and SVM-WOA, are developed in this study for $B B$ magnitude forecasts. The objective of the MFO and WOA systems is to optimize the SVM parameters, including ' $C$ ' and ' $\varepsilon$ ', to observe more eminent performance capabilities for forecast views. Tuning and optimizing SVM parameters by optimization algorithms has been used by researchers for improving the performance of the base model (SVM).

The following explains the remainder of this paper. First, the case study of this research and the methods of the data collection are presented. Second, the structure of the SVM model and its optimizers (MFO and WOA) is presented. Third, the results of this study are presented, evaluated, and discussed. Finally, a summary of this paper is presented in the Section 7. 
Table 1. Some recent ML and AI studies on the $B B$ prediction.

\begin{tabular}{|c|c|c|c|}
\hline Method & Study & Input & Dataset Size \\
\hline FIS & Monjezi, Rezaei and Yazdian [14] & $\begin{array}{l}\text { Burden, charge per delay, hole depth, } \\
\text { powder factor, rock density, spacing, } \\
\text { specific drilling, stemming }\end{array}$ & - \\
\hline ANN-GA & Monjezi et al. [42] & $\begin{array}{l}\text { Burden, charge per delay, hole } \\
\text { diameter, hole length, powder factor, } \\
\text { rock mass rating, spacing, } \\
\text { specific drilling }\end{array}$ & 195 \\
\hline ANN & $\begin{array}{c}\text { Monjezi, Ahmadi, Varjani and } \\
\text { Khandelwal [13] }\end{array}$ & $\begin{array}{l}\text { Burden, charge per delay, hole depth, } \\
\text { hole diameter, powder factor, spacing, } \\
\text { specific drilling, stemming, uniaxial } \\
\text { compressive strength } \\
\text { water content }\end{array}$ & 97 \\
\hline ANN & Sayadi et al. [43] & $\begin{array}{l}\text { Burden, hole depth, spacing, specific } \\
\text { charge, specific drilling }\end{array}$ & 103 \\
\hline SVM & $\begin{array}{l}\text { Mohammadnejad, Gholami, } \\
\text { Sereshki and Jamshidi [2] }\end{array}$ & $\begin{array}{l}\text { Burden, hole depth, powder factor, } \\
\text { spacing, specific drilling, stemming }\end{array}$ & 193 \\
\hline SVM & Khandelwal and Monjezi [12] & $\begin{array}{l}\text { Burden, hole length, powder factor, } \\
\text { spacing, specific drilling, stemming }\end{array}$ & 234 \\
\hline ANN & Monjezi et al. [44] & $\begin{array}{l}\text { Burden, delay per burden, number of } \\
\text { rows, powder factor } \\
\text { rock factor, spacing, } \\
\text { specific drilling, stemming }\end{array}$ & - \\
\hline ANN, neuro-fuzzy & $\begin{array}{c}\text { Esmaeili, Osanloo, Rashidinejad, } \\
\text { Bazzazi and Taji [3] }\end{array}$ & $\begin{array}{l}\text { Charge last row, number of rows, } \\
\text { specific charge, stemming }\end{array}$ & 42 \\
\hline $\mathrm{ANN}, \mathrm{ABC}$ & Ebrahimi et al. [45] & $\begin{array}{l}\text { Burden, hole depth, powder factor, } \\
\text { spacing, stemming length }\end{array}$ & 34 \\
\hline GP & Faradonbeh et al. [46] & $\begin{array}{l}\text { Burden, powder factor, spacing, } \\
\text { stemming, stiffness ratio }\end{array}$ & 175 \\
\hline $\begin{array}{l}\text { fuzzy RES-GA, fuzzy } \\
\text { RES-ICA }\end{array}$ & $\begin{array}{l}\text { Hasanipanah and Bakhshandeh } \\
\text { Amnieh [17] }\end{array}$ & $\begin{array}{l}\text { Burden, blast-hole inclination, burden } \\
\text { to hole diameter ratio, charge per } \\
\text { delay, hole diameter, spacing to } \\
\text { burden ratio, stemming to burden } \\
\text { ratio, velocity of detonation }\end{array}$ & 62 \\
\hline RF & Kumar et al. [47]. & $\begin{array}{c}\text { Spacing to burden ratio, P-wave, hole } \\
\text { length to stemming ratio, } \\
\text { density of explosive }\end{array}$ & 140 \\
\hline SCA-RF, HHO-RF & $\begin{array}{c}\text { Zhou, Dai, Khandelwal, Monjezi, } \\
\text { Yu and Qiu [18] }\end{array}$ & $\begin{array}{l}\text { Burden, hole length, powder factor, } \\
\text { spacing, specific drilling, stemming }\end{array}$ & 234 \\
\hline $\mathrm{ANN}, \mathrm{ACO}$ & Saghatforoush et al. [48] & $\begin{array}{l}\text { Burden, hole length, powder factor, } \\
\text { spacing, stemming length }\end{array}$ & 97 \\
\hline
\end{tabular}

GP: genetic programing, ACO: ant colony optimization, GA: genetic algorithm, ICA: imperialism competitive algorithm, RES: rock engineering system, RF: random forest, HHO: Harris hawks optimizer, SCA: sine cosine algorithm.

\section{Field Observation and Measurement}

The data of this present research were gathered from a blasting operation in Gol-EGohar Iron mine. This mine is situated in Kerman province, Iran (Figure 1). During the blasting operation, the height of the blast holes and diameter were $17 \mathrm{~m}$ and $203 \mathrm{~mm}$, respectively. The lag time between the first and second row was $80 \mathrm{~ms}$. The lag time for the other rows was set as $50 \mathrm{~ms}$. The stemming material used was drilling cuttings. In this mine, the $B B$ phenomenon has worsened and reached up to $20 \mathrm{~m}$ because of its inappropriate blasting patterns. The problem of the $B B$ (with $20 \mathrm{~m}$ ) induced by the blasting operation in the investigated mine is shown in Figure 2. 


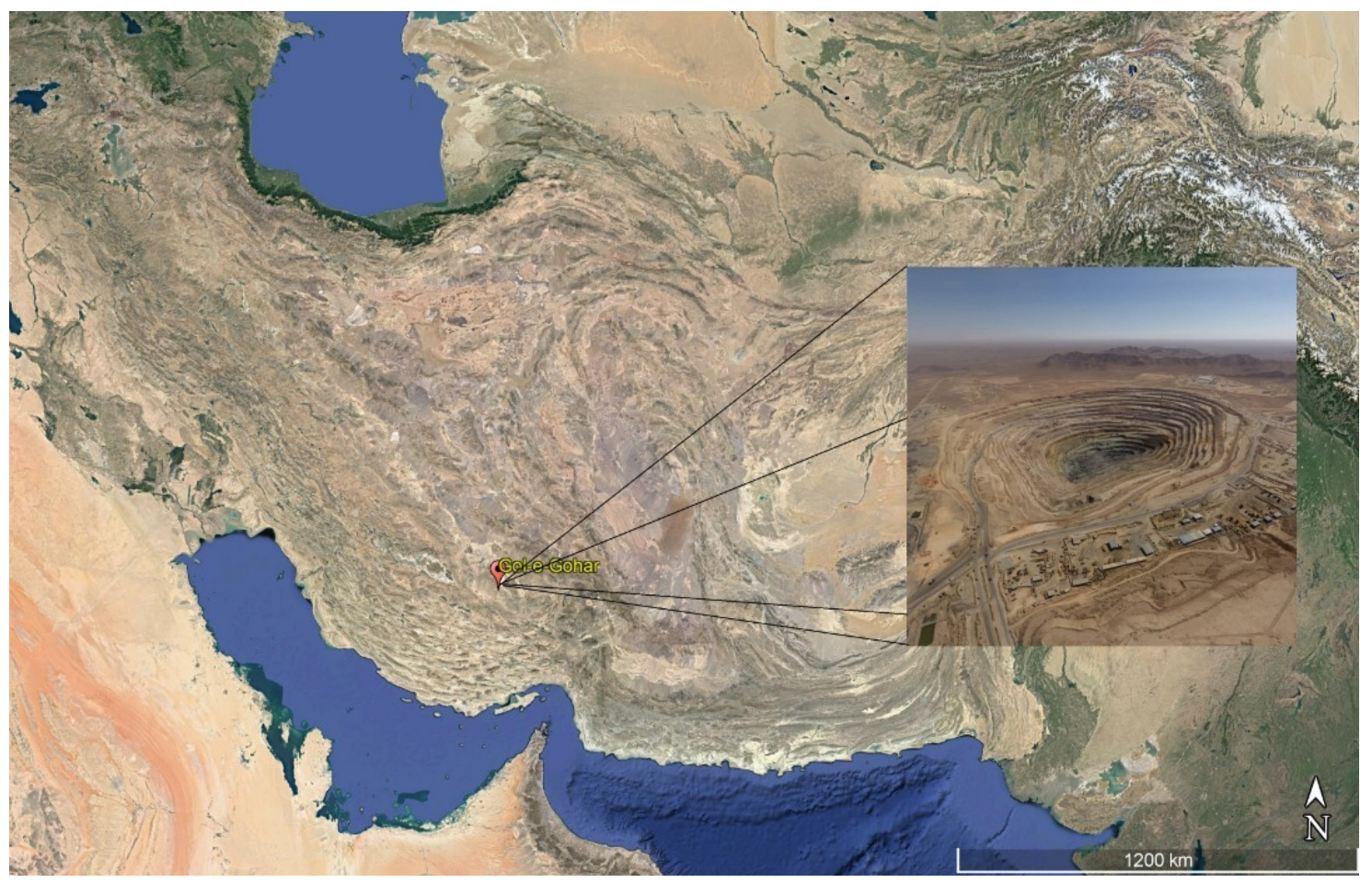

Figure 1. Position of the research area in Iran.

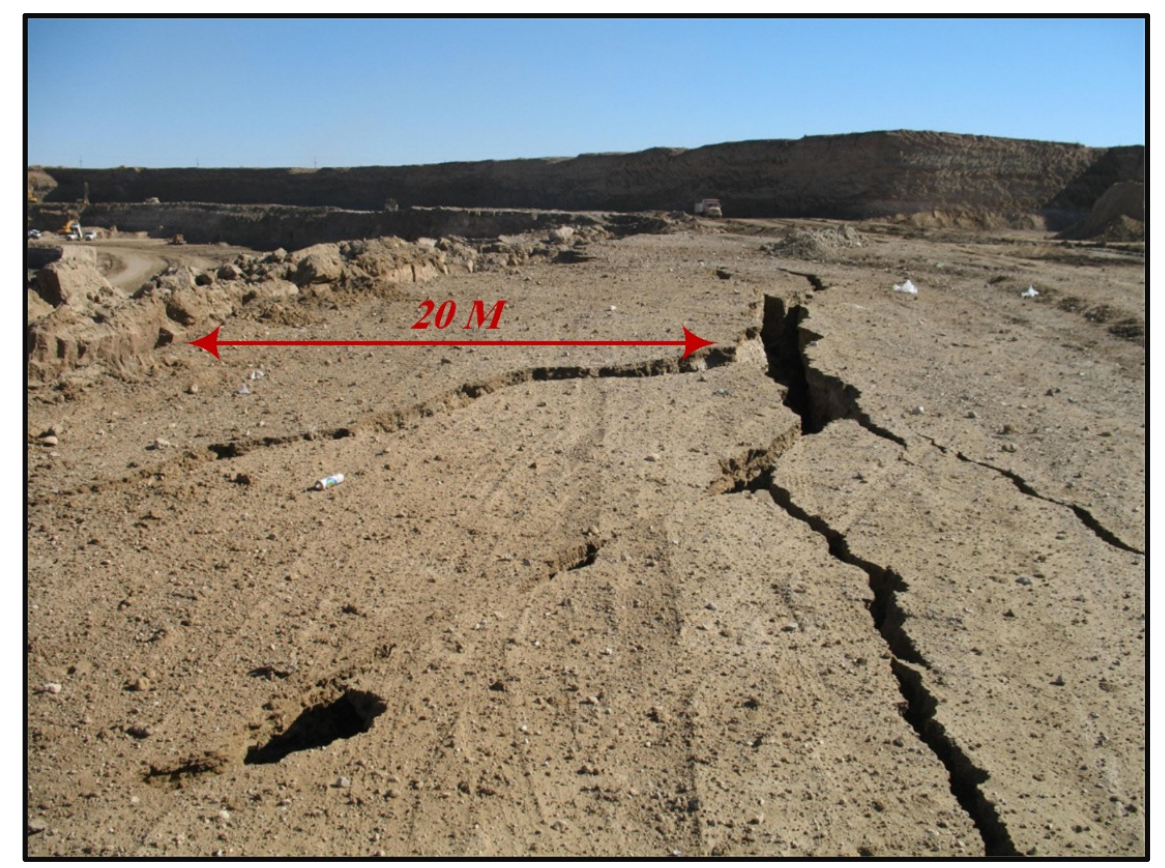

Figure 2. $B B$ problem induced by blasting in the studied mine.

Table 2 demonstrates the scale, unit and symbol of the assessed parameters in the study site together with more information of the $B B$ parameter. In total, 85 blasting events were considered and their data were used in this research for the $B B$ forecast. In the following, the process of selecting the most important parameters among these 10 measured parameters on the $B B$ will be discussed and then the modeling procedure using tree-based models will be described in detail. 
Table 2. Summary of gathered data with their symbol, unit and range.

\begin{tabular}{clcccc}
\hline Parameter & Class & Unit & Acronym & Min & Max \\
\hline Powder factor & Input & $\mathrm{kg} / \mathrm{ton}$ & $\mathrm{PF}$ & 1.90 & 0.30 \\
Burden & Input & $\mathrm{m}$ & $\mathrm{B}$ & 5.00 & 6.50 \\
Spacing to burden ratio & Input & - & $\mathrm{S} / \mathrm{B}$ & 1.18 & 1.30 \\
Number of rows & Input & - & No. row & 2.00 & 5.00 \\
Charge per delay & Input & $\mathrm{Kg}$ & $\mathrm{CPD}$ & 72.00 & 455.96 \\
Last row charge to total charge ratio & Input & - & LRC/TC & 0.04 & 0.55 \\
Stemming to burden ratio & Input & - & $\mathrm{St} / \mathrm{B}$ & 0.80 & 1.60 \\
Joint condition & Input & - & $\mathrm{JC}$ & 1.00 & 4.00 \\
Uniaxial compressive strength & Input & $\mathrm{MPa}$ & $\mathrm{UCS}$ & 55.00 & 90.00 \\
Water height to burden ratio & Input & - & $\mathrm{W} / \mathrm{B}$ & 0.00 & 2.00 \\
Back-break & Target & $\mathrm{m}$ & $\mathrm{BB}$ & 3.00 & 20.00 \\
\hline
\end{tabular}

\section{Methods}

\subsection{SVM}

The SVM is considered as a supervised ML technique that is successfully implemented in the domain of geotechnical and tunnelling engineering [56]. The linear function of SVM can be explained as follow:

$$
f(a)=w \cdot a+d
$$

where $a$ denotes the input variable, $w$ denotes the weight vector, and $d$ points to model error values. SVM strives to decrease the disparity between the real and predicted values. Therefore, SVM predicts according to reducing the objective function, which is an error indicator. Below is the optimization procedure [57]:

$$
\begin{gathered}
\min \frac{1}{2}\|w\|^{2}+c \sum_{i=1}^{k}\left(\xi_{i}^{-}-\xi_{i}^{+}\right) \\
\text {Subject }(\text { to })\left(w x_{i}+d\right)-b_{i}<\varepsilon+\xi_{i}^{+} \\
b_{i}-\left(w_{i} a_{i}+d\right) \leq\left(\varepsilon+\varepsilon_{i}^{-}\right)
\end{gathered}
$$

where $C$ denotes the coefficient of penalty, $k$ means the number of training data, $\xi_{i}^{-}$and $\xi_{i}^{+}$ signify the data violations whose various values are higher than $\xi$ the allowed range with observable values, and $w_{i}, a_{i}$, and $b_{i}$ refer to the variables' weight, the input variable, and the target observation. Equations (2) and (3) are used to estimate the values of $w$ and $d$ and are then replaced into Equation (1). In SVM, to represent the input data points to a high-dimensional feature space, the kernel function can be employed. The kernels are able to resolve the issues with numerous dimensions. A total of four well-known SVM kernels are used, including sigmoid, linear, polynomial, and radial basis function (RBF). In this study, the RBF kernel was used since this kernel was proved to possess a desirable generalization capability for various types of datasets. Thus, Equation (1) is regarded as follows:

$$
\begin{gathered}
f(a)=w \cdot H\left(a, a_{i}\right)+d \\
H\left(a, a_{i}\right)=\exp \left(-\frac{a-a_{i}}{2 \gamma^{2}}\right)
\end{gathered}
$$

where $H\left(a, a_{i}\right)$ stands for the kernel function, and $\gamma$ signifies the kernel function's parameter. SVM parameters such as $C$ and $\varepsilon$ have unknown values and are assumed as decision variables. Thus, they should enter the optimization process. The aim of hybrid SVM, MFO, and WOA is to determine the precise value of the parameters mentioned above and predict $B B$ by SVM. Figure 3 indicates the optimization process employed by each optimization method, including WOA and MFO, as well as their functions in two combined models of SVM-MFO and SVM-WOA to forecast $B B$ values. 


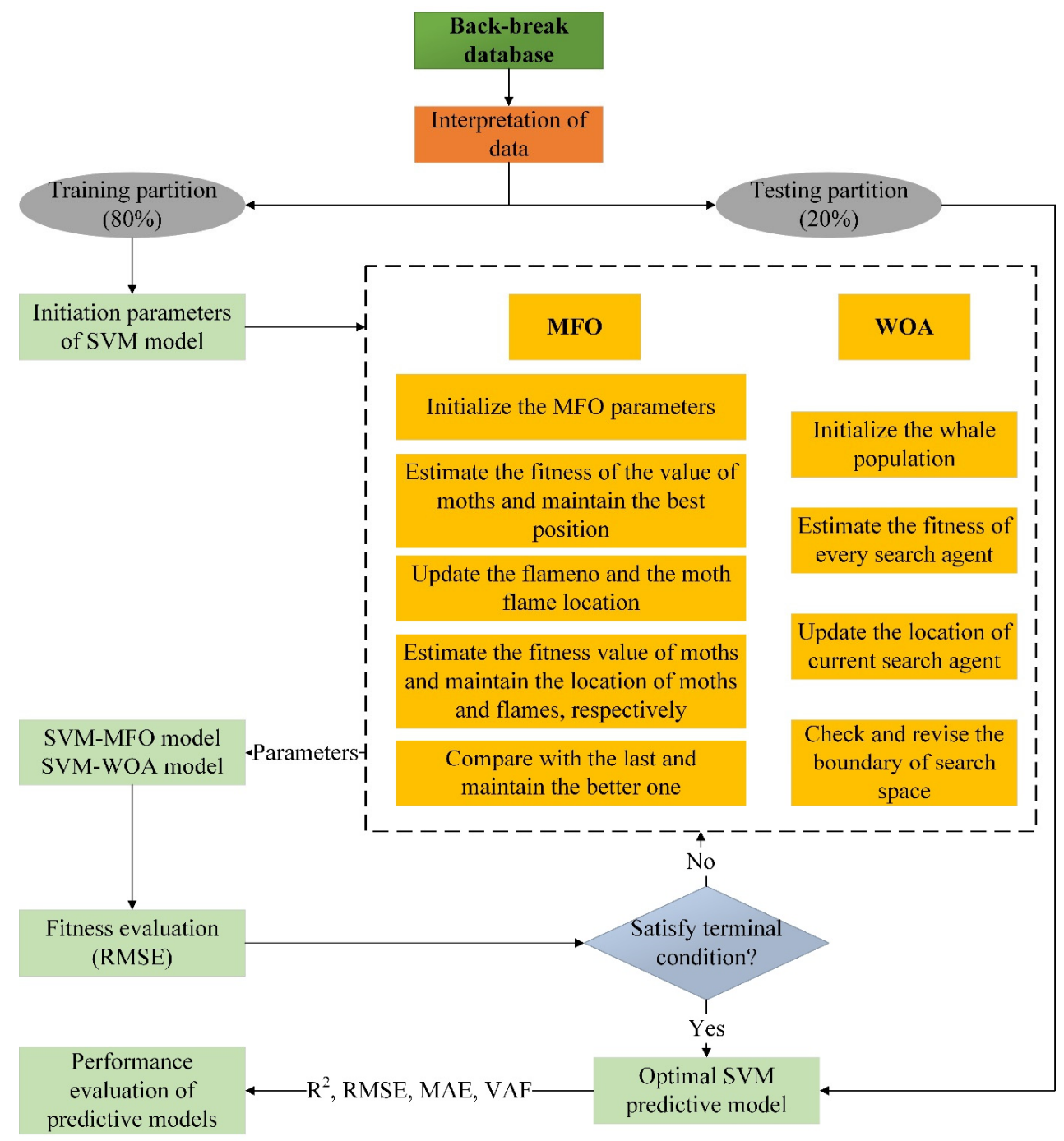

Figure 3. Flowchart of this investigation.

\section{2. $M F O$}

MFO is one of the most effective optimization algorithms that mimics the fly styles of moths in the darkness. Typically, moths try to keep a fixed position to the moon for shuttling at nighttime [58]. They engage a method defined as a transverse orientation to navigate. Nevertheless, sometimes this method is useless, and especially so for straight movement if the light origin is extremely far away. If moths find irregular lighting, they endeavor to preserve an analogous form with the brightness to pass it in a straight way. Notwithstanding that this bright origin is closer to the moths than the moon, holding a comparable angle to the origin of light creates an incompetent or killing spiral fly-path for moths. This sort of killing flow, while the origin of light is close, is used to determine the optimization problems in the actual practice. In this method, the probable answers are moths, and variables are moths' coordinate vectors in the exploration space. The MFO equation used for optimizing SVM is presented in Equation (7).

$$
\text { Flame number }=\operatorname{round}\left(N-m * \frac{N-1}{Q}\right)
$$

where $m$ indicates the current number of repetitions, the highest quantity of flames is represented by $N$, and $Q$ implies the largest number of repetitions. 


\subsection{WOA}

The WOA is an optimization approach that imitates the humpback whale's social practice in following their hunt in seas [59]. This algorithm utilizes a different method following the particular bubble net and the feeding habits of the whale. The WOA method comprises three principal activities, including encircling prey, bubble-net attacking (Equation (8)) and prey exploring (Equation (9)). Here is the mathematical presentation of these activities.

$$
\begin{gathered}
X^{s+1}=\left\{\begin{array}{c}
X_{\text {gbest }}^{s}-F \cdot\left|M \cdot X_{\text {gbest }}^{s}-X^{s}\right|, p<0.5 \\
X_{\text {gbest }}^{s}+Q \cdot e^{b l} \cdot \cos (2 \pi l), p \geq 0.5
\end{array}\right. \\
X^{s+1}=X_{\text {rand }}^{s}-F \cdot\left|M \cdot X_{\text {rand }}^{s}-X^{s}\right|
\end{gathered}
$$

where $s$ refers to the present repetition, $X^{s}$ is the existing position vector, $X^{s+1}$ is the new position, $X_{\text {gbest }}^{s}$ represents the existing position of the best solution achieved, $F$ and $M$ are the coefficient vectors, $l$ stands for an arbitrary number within $[-1,1], b$ signifies a constant for limiting the form of the logarithmic spiral, $p$ signifies an arbitrary number within $[0,1]$, $X_{\text {rand }}^{s}$ denotes a position vector of a whale individual at random selected from the existing inhabitants, and $Q=\left|X_{\text {gbest }}^{s}-X_{s}\right|$ stands for the space between the whale and the target.

Every humpback whale signifies an individual, and the location of every individual in the search space describes a solution. The whale can know the position of the prey and circle the prey within the echolocation (encircling prey). The whale strikes the target by spiraling up and constantly narrowing the circling (bubble-net attacking). If the coefficient vector $|F|>1$, it indicates that the whale moves beyond the lessening encircling circle. At this point in time, the humpback whale explores arbitrarily based on every other's position.

\section{SVM Optimized Models}

For developing the optimized SVM models, the aim of employing WOA and MFO algorithms is to optimize the SVM hyperparameters ' $\varepsilon$ ' and ' $C$ '. The values of these parameters were set within the following ranges:

- $\quad$ C: 0.01-100;

- $\quad \varepsilon: 0.01-50$.

The key procedure of optimizing SVM parameters utilizing WOA and MFO optimization methods is indicated in Figure 4. The first step involved is preparing the data and dividing it into training and testing sets. The second step involved is assigning appropriate values to the WOA and MFO parameters. In the third step, RMSE was used as an indicator for assessing the models' fitness. The parameters were revised based on the outcomes of each repetition in the fourth step. In the final step, the most suitable values for the parameters were achieved, and the stopping conditions were met.

1. Data preparation

2. Initialization parameters

3. Fitness evaluation

4. Update parameters

5. Stop condition checking

\section{The dataset is arbitrary split into training and testing sets based} on a proper proportion.

Established MFO and WOA parameters.

Determine the fitness function and assess its fitness ere optimizing the target parameter value.

Based on the outcomes of each repetition, modify the optimization requirements that the hyperparameters fulfil.

Once the optimization stop condition is met, the most suitable

parameters are achieved.

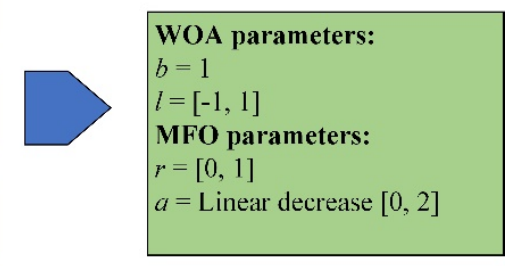

Figure 4 . The primary procedure of optimizing parameters of SVM. 


\section{Results and Discussions}

\subsection{Feature Selection}

An evolutionary random forest (ERF) technique was employed to select the most significant factors for $B B$ prediction. This model was applied to ten candidate inputs, including PF, B, S/B, No. row, CPD, LRC/TC, St/B, JC, and UCS. The ERF selected five important inputs, including PF, No. row, CPD, LRC/TC, and St/B. These inputs were used to develop the SVM model and its optimized variants. This model was ran using the parameters shown in Figure 5. Figure 6 demonstrates the frequency distribution of each selected input and $B B$. The coefficient of determination $\left(\mathrm{R}^{2}\right)$-linear regression of this model was obtained as 0.909 .

\begin{tabular}{|l|}
\hline \multicolumn{1}{|c|}{ ERF parameters and settings } \\
\hline Minimum number of inputs $=1$ \\
Maximum number of generations $=30$ \\
Maximal fitness $=$ infinity \\
Selection scheme $=$ tournament \\
Tournament size $=0.25$ \\
p-initialize $=0.5$ \\
p-mutation $=-0.1$ \\
p-crossover $=0.5$ \\
Crossover-type $=$ uniform \\
\hline
\end{tabular}

Figure 5. ERF parameters and their associated values.
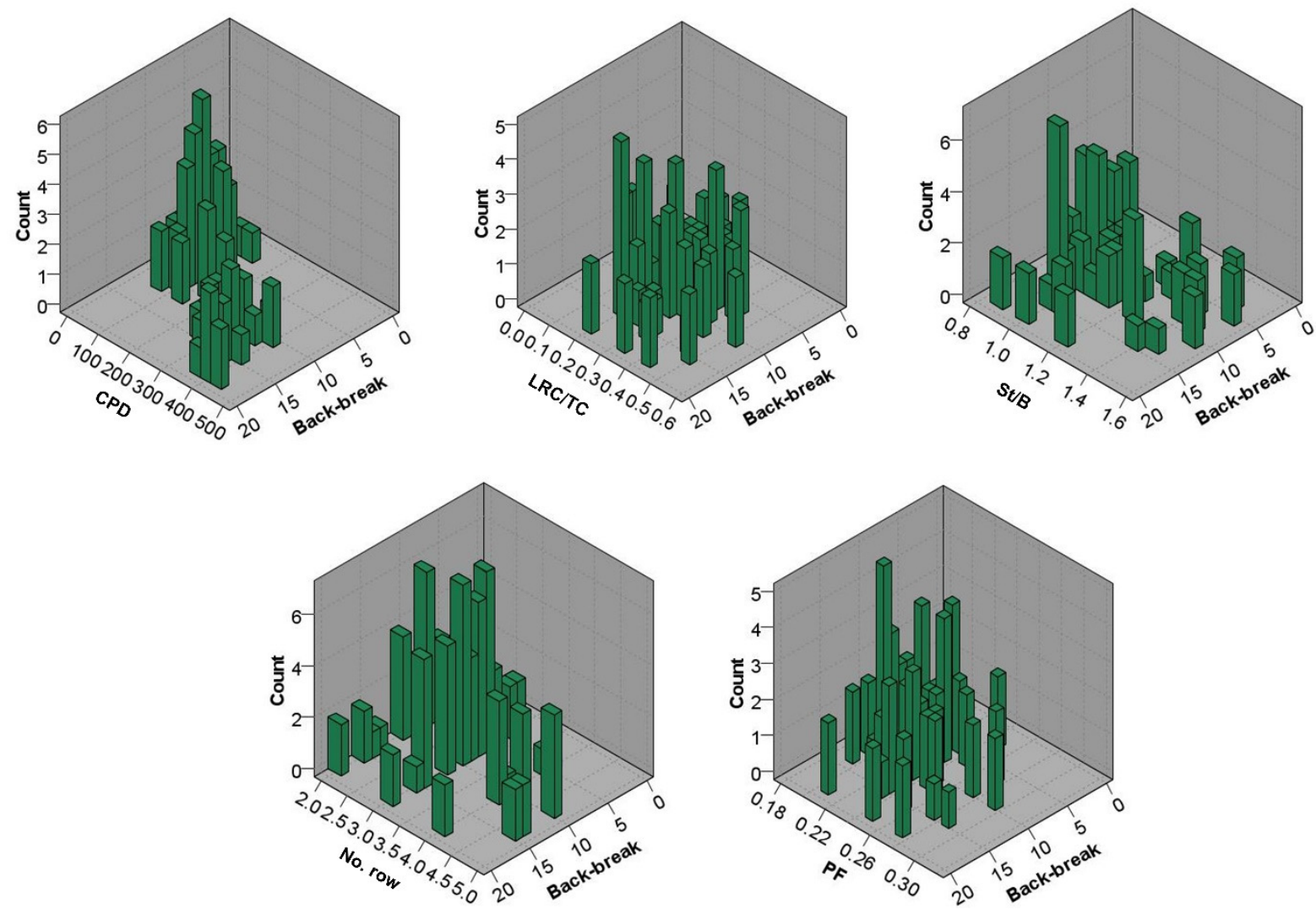

Figure 6. A 3D histogram of each selected input and $B B$. 


\subsection{Models' Development and Evaluation}

Once the models are developed, it is vital to assess the performance of them. To this end, four performance criteria, including $R^{2}$, the mean absolute error $(M A E)$, the root mean squared error (RMSE), and the variance accounted for (VAF), were employed. The formulas for estimating these criteria are shown in Equations (10)-(13). In these equations, $B B_{i}$ is the real value, $B \hat{B}_{i}$ stands for the forecasted value, $\overline{B B_{i}}$ implies the mean of the real values, and $N$ signifies the number of samples in the training or testing phases. It is important to mention that these performance criteria have been used in many published works (e.g., [60-65]).

$$
\begin{gathered}
\text { RMSE }=\sqrt{\frac{1}{N} \sum_{i=1}^{N}\left(\widehat{B B_{i}}-B B_{i}\right)^{2}} \\
R^{2}=1-\frac{\sum_{i=1}^{N}\left(B B_{i}-\widehat{B B_{i}}\right)^{2}}{\sum_{i=1}^{N}\left(B B_{i}-\overline{B B_{i}}\right)^{2}} \\
M A E=\frac{1}{N} \sum_{i=1}^{N}\left|\widehat{B B_{i}-B B_{i}}\right| \\
V A F=\left[1-\frac{\operatorname{var}\left(B B_{i}-\widehat{B B_{i}}\right)}{\operatorname{var}\left(B B_{i}\right)}\right] \times 100
\end{gathered}
$$

Figure 7 shows the association between the predicted and real values of $B B$. The outcomes indicate that the testing and training outcomes of these algorithms are great. The training and test values are scattered adjacent to the best fitting line. Concerning the performance indicators, the forecast performance of the SVM-MFO is somewhat greater than the other model. For the training phase, the $R^{2}$ (linear regression), RMSE, MAE, and $V A F$ values were $0.992,0.364,0.044$, and 99.150, correspondingly. For the testing phase, the $R^{2}, R M S E, M A E$, and VAF values were $0.985,0.629,0.332$, and 98.371 , respectively. It is worth noticing that the SVM-MFO is a more reliable model than the other optimized model for both the training and testing phases. Expectedly, these two hybrid models are capable of considerably improving the performance capability of a single SVM model in predicting $B B$, as displayed in Table 3. For example, the RMSE value can be lessened from 1.714 to below 0.6 (in the training phase) by optimizing the SVM models.

Table 3. Performance of the models developed.

\begin{tabular}{ccccccccc}
\hline Model & \multicolumn{3}{c}{ Training } \\
& $\begin{array}{c}\mathrm{R}^{2} \\
(\text { rank })\end{array}$ & $\begin{array}{c}\text { RMSE } \\
(\text { rank })\end{array}$ & $\begin{array}{c}\text { VAF } \\
(\text { rank })\end{array}$ & $\begin{array}{c}\text { MAE } \\
(\text { rank })\end{array}$ & $\begin{array}{c}\mathrm{R}^{2} \\
(\text { rank })\end{array}$ & $\begin{array}{c}\text { RMSE } \\
\text { (rank) }\end{array}$ & $\begin{array}{c}\text { VAF } \\
(\text { rank })\end{array}$ & $\begin{array}{c}\text { MAE } \\
(\text { rank })\end{array}$ \\
SVM & 0.885 & 1.714 & 88.404 & 1.135 & 0.844 & 1.949 & 82.391 & 1.553 \\
& $(1)$ & $(1)$ & $(1)$ & $(1)$ & $(1)$ & $(1)$ & $(1)$ & $(1)$ \\
SVM- & 0.992 & 0.364 & 99.150 & 0.044 & 0.985 & 0.629 & 98.371 & 0.332 \\
MFO & $(3)$ & $(3)$ & $(3)$ & $(3)$ & $(3)$ & $(3)$ & $(3)$ & $(3)$ \\
SVM- & 0.981 & 0.559 & 98.064 & 0.125 & 0.974 & 0.805 & 97.168 & 0.391 \\
WOA & $(2)$ & $(2)$ & $(2)$ & $(2)$ & $(2)$ & $(2)$ & $(2)$ & $(2)$ \\
\hline
\end{tabular}

Tables 3 and 4 review the performance indicator outcomes $\left(R^{2}, R M S E, M A E\right.$, and VAF) and overall ranking outcomes of the standard SVM and two hybrid models in forecasting $B B$. The joining outcomes of the training and testing sets are that the total ranking of SVMMFO is superior. This explains that the SVM-MFO gives greater precision and robustness in forecasting $B B$ compared to the SVM-WOA. 

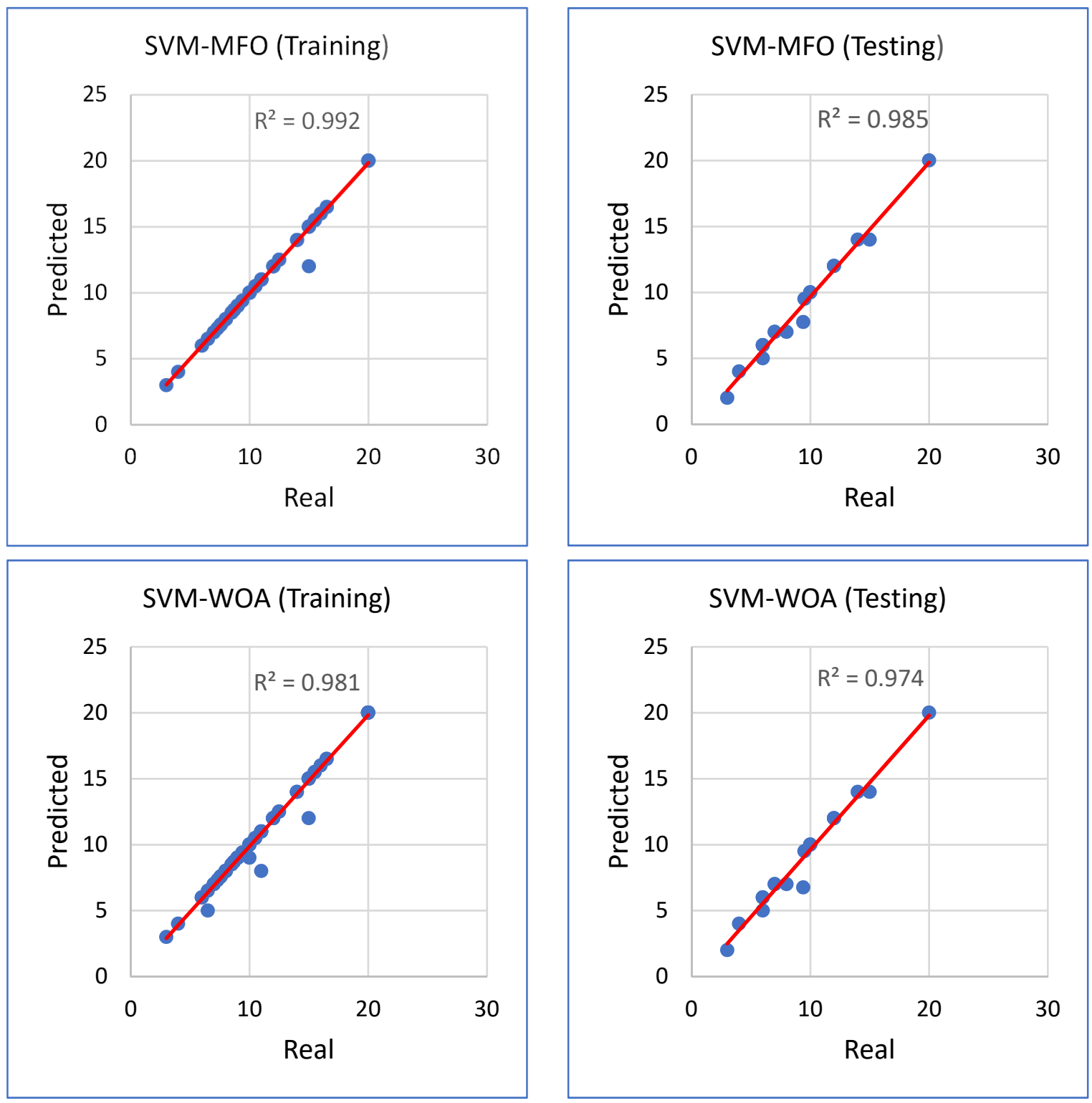

Figure 7. Real and predicted values of $B B$ using different SVM-based models.

Table 4. Total ranking of the models developed.

\begin{tabular}{cccc}
\hline & Training Rank & Testing Rank & Total Rank \\
\hline SVM & 4 & 4 & 8 \\
SVM-MFO & 12 & 12 & 24 \\
SVM-WOA & 8 & 8 & 16 \\
\hline
\end{tabular}

The performance of the two models established in this research was also compared with two more well-known SVM optimized models, including SVM-particle swarm optimization (PSO) and SVM-cuckoo optimization algorithm (COA). The outcomes of this comparison are displayed in Figure 8. The parallel graph outcomes explain that the forecast performance of the SVM models established in this research is more precise than the other algorithms. Amongst all the models, the SVM-MFO is more reliable. According to the findings of this study, it is evident that the SVM-MFO has excellent learning and forecast capacities. Hence, this present study suggests employing the developed SVM-MFO model for $B B$ prediction. 
Legend

- SVM-COA - SVM-MFO - SVM-PSO - SVM-WOA

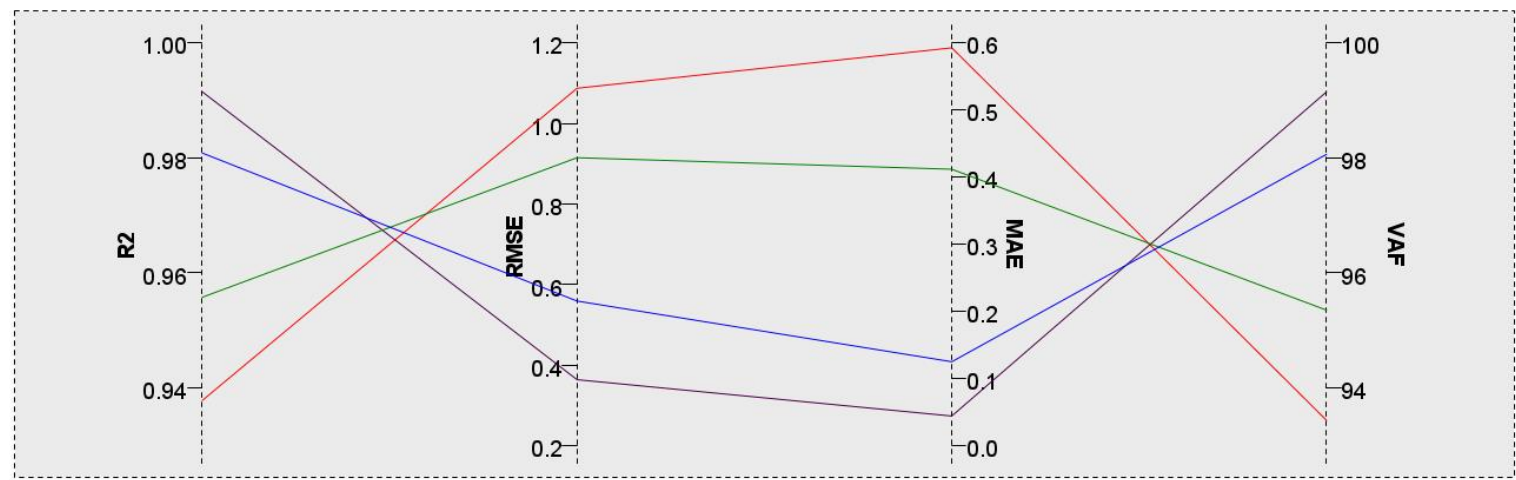

Figure 8. Performance of models developed in this investigation (training phase).

The data used in this study were also used by Monjezi and Dehghani [66]. They did not employ a feature selection technique and used seven inputs for developing neural network models. The best values of $R^{2}$ and RMSE that they achieved were 0.972 and 0.643 , respectively. For both training and testing, the $R^{2}$ of SVM-MFO is better than those presented by Monjezi and Dehghani [60]. In addition, these data were used by Monjezi, Rezaei and Yazdian [14], and they applied fuzzy set theory and MR models to eight inputs. Their best $R^{2}$ value was 0.954 . This comparison shows that despite the usage of fewer inputs for developing the SVM-MFO, this model showed better performance than the models developed in the above studies. It is important to mention that one of the shortcomings and disadvantages of ML and AI models is their limited practical application. We as engineers should always try to make them as simple as possible in practice for other researchers and designers. In this way, one of the possible options is related to the number of inputs that we need to give to the system. The level of complexity can be decreased by reducing the number of input parameters. Another point is related to the fact that if a lower number of inputs are needed to be collected, the process of data collection would be easier and faster compared with the situation in which we need to collect and have all inputs.

\section{Analysis of Sensitivity}

In mechanical tunnel engineering, the forecast of a $B B$ is the solution under specific rock circumstances. Different determinants of $B B$ should be systematically examined to forecast the $B B$ precisely and decrease the great cost and danger of tunnel building. It can be identified that whole inputs, namely PF, No. row, CPD, LRC/TC, and St/B, contribute to the $B B$ forecast. Nevertheless, the sensitivity of every input is ambiguous and requires further investigation.

In this part, the mutual information (MI) test method [67] is employed for examining the significance of $B B$ factors and their sensitivity. $\mathrm{MI}$ is a filtering technique that obtains the arbitrary connection between inputs and the target. MI tests the dependence among variables and shows the intensity of the association among them. The MI magnitude among variables is estimated by means of the information gain:

$$
\operatorname{Gain}(A, B)=\operatorname{Ent}(A)-\sum_{s-1}^{S} \frac{\left|A^{s}\right|}{|A|} \operatorname{Ent}\left(A^{s}\right)
$$

where $s$ denotes the number of all probable values of $B$, As is the set of $A$ when $B$ takes the value $B s$, and $\operatorname{Ent}(A)$ signifies the information entropy. The larger the value of gain $(A, B)$, the better the relationship between $B$ and $A$.

Finally, based on the variable score in the MI examination, the significance intensity of the input that forecasts $B B$ was ascertained. The results of this analysis are indicated in Figure 9. The most crucial variables for forecasting $B B$ were $\mathrm{CPD}, \mathrm{PF}$, and St/B. Their 
significance scores were 59.52, 15.09, and 11.92 , respectively. The lowest score belonged to LRC/TC (significance score $=2.94$ ). Nevertheless, it should be mentioned that inputs, such as LRC/TC and No. row, still have a deep influence on $B B$.

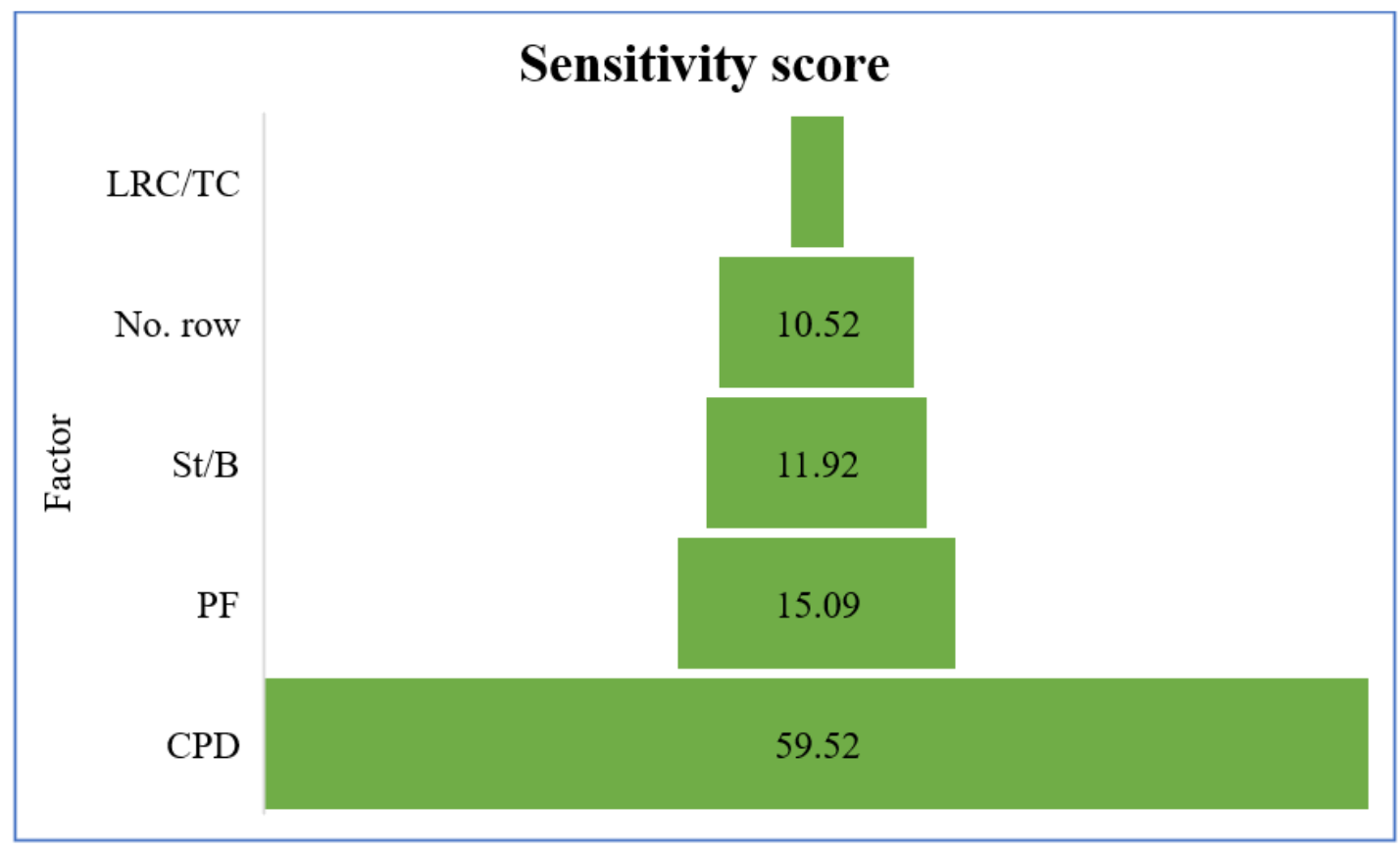

Figure 9. Analysis of sensitivity of five factors on $B B$.

\section{Conclusions}

This study attempts to hybridize the SVM algorithm with well-known and efficient optimization algorithms in the domain of $B B$ prediction. To achieve this goal, two renowned optimization algorithms, including WOA and MFO, which were effectively investigated by previous scientists, were chosen and integrated with SVM, and later, SVM-MFO and SVM-WOA were built for forecasting intentions. The models were built employing ten inputs and one target, which was $B B$. Before the models' development, an ERF was used as the feature selection method to lessen the data dimensionality and identify the most relevant inputs for $B B$ prediction. The inputs selected by this technique were PF, No. row, $\mathrm{CPD}, \mathrm{LRC} / \mathrm{TC}$, and St/B. To appraise the performance of the developed models, several measures were employed, including $R^{2}, R M S E, V A F$, and MAE. Additionally, for the purpose of comparison, the authors have forecasted $B B$ developing different models, including standard SVM, SVM-PSO, and SVM-COA. Finally, following the evaluation of the performance of the entire implemented and built models, it was discovered that the SVM-MFO had an $R^{2}$ of (0.992 and 0.985), RMSE of (0.364 and 0.629), VAF of (99.150 and 98.371), and $M A E$ of (0.044 and 0.332), correspondingly, for training and test phases, which are better results than those of other employed projecting methods. Consequently, the model offered in this research can be employed in different schemes relating $B B$ s for forecasting their accomplishments. By administering the sensitivity investigation, the relevance score of all inputs was achieved utilizing the MI method. This method was executed among those five variables that were identified by the ERF technique. The importance scores of LRC/TC, No. row, St/B, PF, and CPD were 2.94, 10.52, 11.92, 15.09, and 59.52. These results proved that $\mathrm{CPD}, \mathrm{PF}$, and $\mathrm{St} / \mathrm{B}$ variables are regarded as greatly sensitive determinants on $B B$. Nevertheless, it should be mentioned that additional data and examination are required to analyze the $B B$ under different, severe circumstances. Hence, the employment of the integrated model offered in this article is solely advised under comparable circumstances and in a consistent range of data. Future studies should employ datasets with more data and inputs to enhance the predictive capability of the model. Furthermore, AI-based systems cannot entirely substitute conventional practical techniques. 
Regarding geotechnical engineering, the potential advancement path of AI technology is a mixed method, which simply evolves in the direction of decision support instruments. Prominently, the smart systems employed are just suggested to be implemented under comparable circumstances in this research. The principal weakness of such methods in the geotechnical domain can be regarded as site-specific data employed in developing AI models. The geotechnical data and measurements can vary from location to location, and because of this issue, the generalization of the developed AI models is a challenging task.

Author Contributions: Conceptualization, D.J.A., M.M. and H.D.; methodology, Q.Y., D.J.A. and A.S.M.; software, Q.Y., D.J.A. and A.S.M.; formal analysis, Q.Y., D.J.A. and A.S.M.; writing-original draft preparation, Q.Y., D.J.A., A.S.M., M.M., H.D. and D.V.U.; writing—review and editing, H.D., A.S.M., D.J.A., M.M. and D.V.U.; supervision, D.J.A., M.M., A.S.M. and H.D.; data curation, M.M. and H.D. All authors have read and agreed to the published version of the manuscript.

Funding: The research was funded by Act 211 Government of the Russian Federation, contract No. 02.A03.21.0011.

Institutional Review Board Statement: Not applicable.

Informed Consent Statement: Not applicable.

Data Availability Statement: The data are available upon request.

Conflicts of Interest: The authors declare no conflict of interest.

\section{References}

1. Jimeno, C.L.; Jimeno, E.L.; Carcedo, F.J.A. Drilling and Blasting of Rocks; Balkema: Rotterdam, The Netherlands, 1995; pp. 183-184. [CrossRef]

2. Mohammadnejad, M.; Gholami, R.; Sereshki, F.; Jamshidi, A. A new methodology to predict backbreak in blasting operation. Int. J. Rock Mech. Min. Sci. 2013, 60, 75-81. [CrossRef]

3. Esmaeili, M.; Osanloo, M.; Rashidinejad, F.; Bazzazi, A.A.; Taji, M. Multiple regression, ANN and ANFIS models for prediction of backbreak in the open pit blasting. Eng. Comput. 2014, 30, 549-558. [CrossRef]

4. Konya, C.J.; Walter, E.J. Surface Blast Design; Prentice Hall: Englewood Cliffs, NJ, USA, 1990.

5. Bhandari, S. Engineering Rock Blasting Operations; A.A. Balkema: Rotterdam, The Netherlands, 1997.

6. Agrawal, H.; Mishra, A. Modified scaled distance regression analysis approach for prediction of blast-induced ground vibration in multi-hole blasting. J. Rock Mech. Geotech. Eng. 2019, 11, 202-207. [CrossRef]

7. Jayasinghe, B.; Zhao, Z.; Chee, A.G.T.; Zhou, H.; Gui, Y. Attenuation of rock blasting induced ground vibration in rock-soil interface. J. Rock Mech. Geotech. Eng. 2019, 11, 770-778. [CrossRef]

8. Armaghani, D.J.; Koopialipoor, M.; Bahri, M.; Hasanipanah, M.; Tahir, M.M. A SVR-GWO technique to minimize flyrock distance resulting from blasting. Bull. Int. Assoc. Eng. Geol. Environ. 2020, 79, 4369-4385. [CrossRef]

9. Gates, W.C.; Ortiz, L.T.; Florez, R.M. Analysis of rockfall and blasting backbreak problems, US 550, Molas Pass, CO. In Proceedings of the Alaska Rocks 2005 the 40th US Symposium on Rock Mechanics (USRMS), Anchorage, AK, USA, $25-29$ June 2005.

10. Kumar, R.; Choudhury, D.; Bhargava, K. Determination of blast-induced ground vibration equations for rocks using mechanical and geological properties. J. Rock Mech. Geotech. Eng. 2016, 8, 341-349. [CrossRef]

11. Bhagade, N.V.; Murthy, V.M.S.R. Controlling backbreak and enhancing fragmentation in dragline bench blasting-A geoengineering approach. Arab. J. Geosci. 2020, 13, 304. [CrossRef]

12. Khandelwal, M.; Monjezi, M. Prediction of Backbreak in Open-Pit Blasting Operations Using the Machine Learning Method. Rock Mech. Rock Eng. 2012, 46, 389-396. [CrossRef]

13. Monjezi, M.; Ahmadi, Z.; Varjani, A.Y.; Khandelwal, M. Backbreak prediction in the Chadormalu iron mine using artificial neural network. Neural Comput. Appl. 2013, 23, 1101-1107. [CrossRef]

14. Monjezi, M.; Rezaei, M.; Yazdian, A. Prediction of backbreak in open-pit blasting using fuzzy set theory. Expert Syst. Appl. 2010, 37, 2637-2643. [CrossRef]

15. Faramarzi, F.; Farsangi, M.A.E.; Mansouri, H. An RES-Based Model for Risk Assessment and Prediction of Backbreak in Bench Blasting. Rock Mech. Rock Eng. 2013, 46, 877-887. [CrossRef]

16. Sari, M.; Ghasemi, E.; Ataei, M. Stochastic Modeling Approach for the Evaluation of Backbreak due to Blasting Operations in Open Pit Mines. Rock Mech. Rock Eng. 2014, 47, 771-783. [CrossRef]

17. Hasanipanah, M.; Amnieh, H.B. Developing a new uncertain rule-based fuzzy approach for evaluating the blast-induced backbreak. Eng. Comput. 2021, 37, 1879-1893. [CrossRef]

18. Zhou, J.; Dai, Y.; Khandelwal, M.; Monjezi, M.; Yu, Z.; Qiu, Y. Performance of Hybrid SCA-RF and HHO-RF Models for Predicting Backbreak in Open-Pit Mine Blasting Operations. Nat. Resour. Res. 2021, 30, 4753-4771. [CrossRef]

19. Sharma, M.; Agrawal, H.; Choudhary, B.S. Multivariate regression and genetic programming for prediction of backbreak in open-pit blasting. Neural Comput. Appl. 2021. [CrossRef] 
20. Khandelwal, M.; Singh, T.N. Prediction of Blast Induced Air Overpressure in Opencast Mine. Noise Vib. Worldw. 2005, 36, 7-16. [CrossRef]

21. Armaghani, D.J.; Momeni, E.; Abad, S.V.A.N.K.; Khandelwal, M. Feasibility of ANFIS model for prediction of ground vibrations resulting from quarry blasting. Environ. Earth Sci. 2015, 74, 2845-2860. [CrossRef]

22. Qiu, Y.; Zhou, J.; Khandelwal, M.; Yang, H.; Yang, P.; Li, C. Performance evaluation of hybrid WOA-XGBoost, GWO-XGBoost and BO-XGBoost models to predict blast-induced ground vibration. Eng. Comput. 2021. [CrossRef]

23. Rezaeineshat, A.; Monjezi, M.; Mehrdanesh, A.; Khandelwal, M. Optimization of blasting design in open pit limestone mines with the aim of reducing ground vibration using robust techniques. Géoméch. Geophys. Geo-Energy Geo-Resour. 2020, 6, 40. [CrossRef]

24. Yu, Z.; Shi, X.; Miao, X.; Zhou, J.; Khandelwal, M.; Chen, X.; Qiu, Y. Intelligent modeling of blast-induced rock movement prediction using dimensional analysis and optimized artificial neural network technique. Int. J. Rock Mech. Min. Sci. 2021, 143, 104794. [CrossRef]

25. Yang, H.; Zeng, Y.; Lan, Y.; Zhou, X. Analysis of the excavation damaged zone around a tunnel accounting for geostress and unloading. Int. J. Rock Mech. Min. Sci. 2014, 69, 59-66. [CrossRef]

26. Yang, H.; Li, Z.; Jie, T.; Zhang, Z. Effects of joints on the cutting behavior of disc cutter running on the jointed rock mass. Tunn. Undergr. Space Technol. 2018, 81, 112-120. [CrossRef]

27. Yang, H.; Xing, S.; Wang, Q.; Li, Z. Model test on the entrainment phenomenon and energy conversion mechanism of flow-like landslides. Eng. Geol. 2018, 239, 119-125. [CrossRef]

28. Yang, H.; Wang, Z.; Song, K. A new hybrid grey wolf optimizer-feature weighted-multiple kernel-support vector regression technique to predict TBM performance. Eng. Comput. 2020. [CrossRef]

29. Liu, B.; Yang, H.; Karekal, S. Effect of Water Content on Argillization of Mudstone During the Tunnelling process. Rock Mech. Rock Eng. 2020, 53, 799-813. [CrossRef]

30. Zhou, J.; Shen, X.; Qiu, Y.; Li, E.; Rao, D.; Shi, X. Improving the efficiency of microseismic source locating using a heuristic algorithm-based virtual field optimization method. Géoméch. Geophys. Geo-Energy Geo-Resour. 2021, 7, 89. [CrossRef]

31. Zhou, J.; Qiu, Y.; Khandelwal, M.; Zhu, S.; Zhang, X. Developing a hybrid model of Jaya algorithm-based extreme gradient boosting machine to estimate blast-induced ground vibrations. Int. J. Rock Mech. Min. Sci. 2021, 145, 104856. [CrossRef]

32. Zhou, J.; Li, X.; Mitri, H.S. Classification of Rockburst in Underground Projects: Comparison of Ten Supervised Learning Methods. J. Comput. Civ. Eng. 2016, 30, 04016003. [CrossRef]

33. Zhou, J.; Chen, C.; Wang, M.; Khandelwal, M. Proposing a novel comprehensive evaluation model for the coal burst liability in underground coal mines considering uncertainty factors. Int. J. Min. Sci. Technol. 2021, 31, 799-812. [CrossRef]

34. Li, Y.; Hishamuddin, F.N.S.; Mohammed, A.S.; Armaghani, D.J.; Ulrikh, D.V.; Dehghanbanadaki, A.; Azizi, A. The Effects of Rock Index Tests on Prediction of Tensile Strength of Granitic Samples: A Neuro-Fuzzy Intelligent System. Sustainability 2021, 13, 10541. [CrossRef]

35. Parsajoo, M.; Armaghani, D.J.; Mohammed, A.S.; Khari, M.; Jahandari, S. Tensile strength prediction of rock material using non-destructive tests: A comparative intelligent study. Transp. Geotech. 2021, 31, 100652. [CrossRef]

36. Armaghani, D.J.; Harandizadeh, H.; Momeni, E.; Maizir, H.; Zhou, J. An optimized system of GMDH-ANFIS predictive model by ICA for estimating pile bearing capacity. Artif. Intell. Rev. 2021. [CrossRef]

37. Al-Bared, M.A.M.; Mustaffa, Z.; Armaghani, D.J.; Marto, A.; Yunus, N.Z.M.; Hasanipanah, M. Application of hybrid intelligent systems in predicting the unconfined compressive strength of clay material mixed with recycled additive. Transp. Geotech. 2021, 30, 100627. [CrossRef]

38. Mohammed, A.; Asteris, P.; Koopialipoor, M.; Alexakis, D.; Lemonis, M.; Armaghani, D. Stacking Ensemble Tree Models to Predict Energy Performance in Residential Buildings. Sustainability 2021, 13, 8298. [CrossRef]

39. Briševac, Z.; Hrženjak, P.; Buljan, R. Models for estimating uniaxial compressive strength and elastic modulus. Građevinar 2016, 68, 19-28. [CrossRef]

40. Briševac, Z.; Pollak, D.; Maričić, A.; Vlahek, A. Modulus of Elasticity for Grain-Supported Carbonates-Determination and Estimation for Preliminary Engineering Purposes. Appl. Sci. 2021, 11, 6148. [CrossRef]

41. Briševac, Z.; Hrženjak, P.; Cotman, I. Estimate of Uniaxial Compressive Strength and Young's Modulus of the Elasticity of Natural Stone Giallo d'Istria. Procedia Eng. 2017, 191, 434-441. [CrossRef]

42. Monjezi, M.; Khoshalan, H.A.; Varjani, A.Y. Prediction of flyrock and backbreak in open pit blasting operation: A neuro-genetic approach. Arab. J. Geosci. 2012, 5, 441-448. [CrossRef]

43. Sayadi, A.; Monjezi, M.; Talebi, N.; Khandelwal, M. A comparative study on the application of various artificial neural networks to simultaneous prediction of rock fragmentation and backbreak. J. Rock Mech. Geotech. Eng. 2013, 5, 318-324. [CrossRef]

44. Monjezi, M.; Rizi, S.M.H.; Majd, V.J.; Khandelwal, M. Artificial Neural Network as a Tool for Backbreak Prediction. Geotech. Geol. Eng. 2014, 32, 21-30. [CrossRef]

45. Ebrahimi, E.; Monjezi, M.; Khalesi, M.R.; Armaghani, D.J. Prediction and optimization of back-break and rock fragmentation using an artificial neural network and a bee colony algorithm. Bull. Int. Assoc. Eng. Geol. 2016, 75, 27-36. [CrossRef]

46. Faradonbeh, R.S.; Monjezi, M.; Armaghani, D.J. Genetic programing and non-linear multiple regression techniques to predict backbreak in blasting operation. Eng. Comput. 2016, 32, 123-133. [CrossRef]

47. Kumar, S.; Mishra, A.K.; Choudhary, B.S. Prediction of back break in blasting using random decision trees. Eng. Comput. 2021. [CrossRef]

48. Saghatforoush, A.; Monjezi, M.; Faradonbeh, R.S.; Armaghani, D.J. Combination of neural network and ant colony optimization algorithms for prediction and optimization of flyrock and back-break induced by blasting. Eng. Comput. 2015, 32, 255-266. [CrossRef] 
49. Nguyen, H.; Bui, X.-N.; Choi, Y.; Lee, C.W.; Armaghani, D.J. A Novel Combination of Whale Optimization Algorithm and Support Vector Machine with Different Kernel Functions for Prediction of Blasting-Induced Fly-Rock in Quarry Mines. Nat. Resour. Res. 2021, 30, 191-207. [CrossRef]

50. Guo, H.; Nguyen, H.; Bui, X.-N.; Armaghani, D.J. A new technique to predict fly-rock in bench blasting based on an ensemble of support vector regression and GLMNET. Eng. Comput. 2021, 37, 421-435. [CrossRef]

51. Hasanipanah, M.; Monjezi, M.; Shahnazar, A.; Armaghani, D.J.; Farazmand, A. Feasibility of indirect determination of blast induced ground vibration based on support vector machine. Measurement 2015, 75, 289-297. [CrossRef]

52. Armaghani, D.J.; Asteris, P.G.; Askarian, B.; Hasanipanah, M.; Tarinejad, R.; Van Huynh, V. Examining Hybrid and Single SVM Models with Different Kernels to Predict Rock Brittleness. Sustainability 2020, 12, 2229. [CrossRef]

53. Khandelwal, M. Blast-induced ground vibration prediction using support vector machine. Eng. Comput. 2011, 27, 193-200. [CrossRef]

54. Shi, X.-Z.; Zhou, J.; Wu, B.; Huang, D.; Wei, W. Support vector machines approach to mean particle size of rock fragmentation due to bench blasting prediction. Trans. Nonferrous Met. Soc. China 2012, 22, 432-441. [CrossRef]

55. Rad, H.N.; Hasanipanah, M.; Rezaei, M.; Eghlim, A.L. Developing a least squares support vector machine for estimating the blast-induced flyrock. Eng. Comput. 2018, 34, 709-717. [CrossRef]

56. Vapnik, V. The Nature of Statistical Learning Theory; Springer Science \& Business Media: New York, NY, USA, 2013.

57. Feng, Y.; Peng, Y.; Cui, N.; Gong, D.; Zhang, K. Modeling reference evapotranspiration using extreme learning machine and generalized regression neural network only with temperature data. Comput. Electron. Agric. 2017, 136, 71-78. [CrossRef]

58. Mirjalili, S. Moth-flame optimization algorithm: A novel nature-inspired heuristic paradigm. Knowl.-Based Syst. 2015, 89, 228-249. [CrossRef]

59. Mirjalili, S.; Lewis, A. The Whale Optimization Algorithm. Adv. Eng. Softw. 2016, 95, 51-67. [CrossRef]

60. Armaghani, D.J.; Hajihassani, M.; Mohamad, E.T.; Marto, A.; Noorani, S.A. Blasting-induced flyrock and ground vibration prediction through an expert artificial neural network based on particle swarm optimization. Arab. J. Geosci. 2014, 7, 5383-5396. [CrossRef]

61. Armaghani, D.J.; Mohamad, E.T.; Narayanasamy, M.S.; Narita, N.; Yagiz, S. Development of hybrid intelligent models for predicting TBM penetration rate in hard rock condition. Tunn. Undergr. Space Technol. 2017, 63, 29-43. [CrossRef]

62. Armaghani, D.J.; Yagiz, S.; Mohamad, E.T.; Zhou, J. Prediction of TBM performance in fresh through weathered granite using empirical and statistical approaches. Tunn. Undergr. Space Technol. 2021, 118, 104183. [CrossRef]

63. Parsajoo, M.; Armaghani, D.J.; Asteris, P.G. A precise neuro-fuzzy model enhanced by artificial bee colony techniques for assessment of rock brittleness index. Neural Comput. Appl. 2021. [CrossRef]

64. Harandizadeh, H.; Armaghani, D.J.; Asteris, P.G.; Gandomi, A.H. TBM performance prediction developing a hybrid ANFIS-PNN predictive model optimized by imperialism competitive algorithm. Neural Comput. Appl. 2021, 33, 16149-16179. [CrossRef]

65. Armaghani, D.J.; Mohamad, E.T.; Momeni, E.; Narayanasamy, M.S. An adaptive neuro-fuzzy inference system for predicting unconfined compressive strength and Young's modulus: A study on Main Range granite. Bull. Int. Assoc. Eng. Geol. Environ. 2015, 74, 1301-1319. [CrossRef]

66. Monjezi, M.; Dehghani, H. Evaluation of effect of blasting pattern parameters on back break using neural networks. Int. J. Rock Mech. Min. Sci. 2008, 45, 1446-1453. [CrossRef]

67. Verron, S.; Tiplica, T.; Kobi, A. Fault detection and identification with a new feature selection based on mutual information. J. Process. Control 2008, 18, 479-490. [CrossRef] 